\title{
- O parto distócico e as principais emergências obstétricas em equiiinos
}

- Dystocic parturition and main obstetric emergencies in equines

\author{
Nereu Carlos Prestes-CRMV-SP n ${ }^{2} 2839$
}

Professor Assistente Doutor do Departamento de Reprodução

Animal e Radiologia Veterinária - UNESP - Botucatu

* Faculdade de Medicina Veterinária
e Zootecnia - UNESP
Departamento de Reprodução
Animal e Radiologia Veterinária
Distrito de Rubião Júnior
CEP:18618-000 - Botucatu -SP
e-mail: rarv@fmzv.unesp.br

\section{RESUMO}

O presente artigo tem por objetivo rememorar conceitos clássicos a respeito do parto normal e distócico e tece comentários sobre as emergências obstétricas de maior destaque para a espécie eqüina.

Palavras-chave: égua, parto, hemorragia puerperal, prolapsos e lacerações.

\section{Introdução}

O parto normal é definido genericamente como a expulsão do produto para o meio exterior após a ruptura dos envoltórios fetais, ao término do período gestacional. A placenta e os anexos são expelidos de imediato ou algumas horas após a parturição. De modo sintético, o parto caracteriza-se como um fenômeno nervoso, endócrino e mecânico em sincrônica associação (Quadro 1).

O parto na espécie equiina é extremamente rápido e transcorre sob contrações vigorosas da musculatura uterina, abdominal e diafragmática. Os hormônios maternos parecem não exercer muita influência sobre o parto. Os níveis relativamente altos de progestágenos e baixos de estrógeno contrastam com os de outras espécies ani-

\section{Quadro 1.}

Diagrama sumarizado dos fatores maternos reguladores do parto

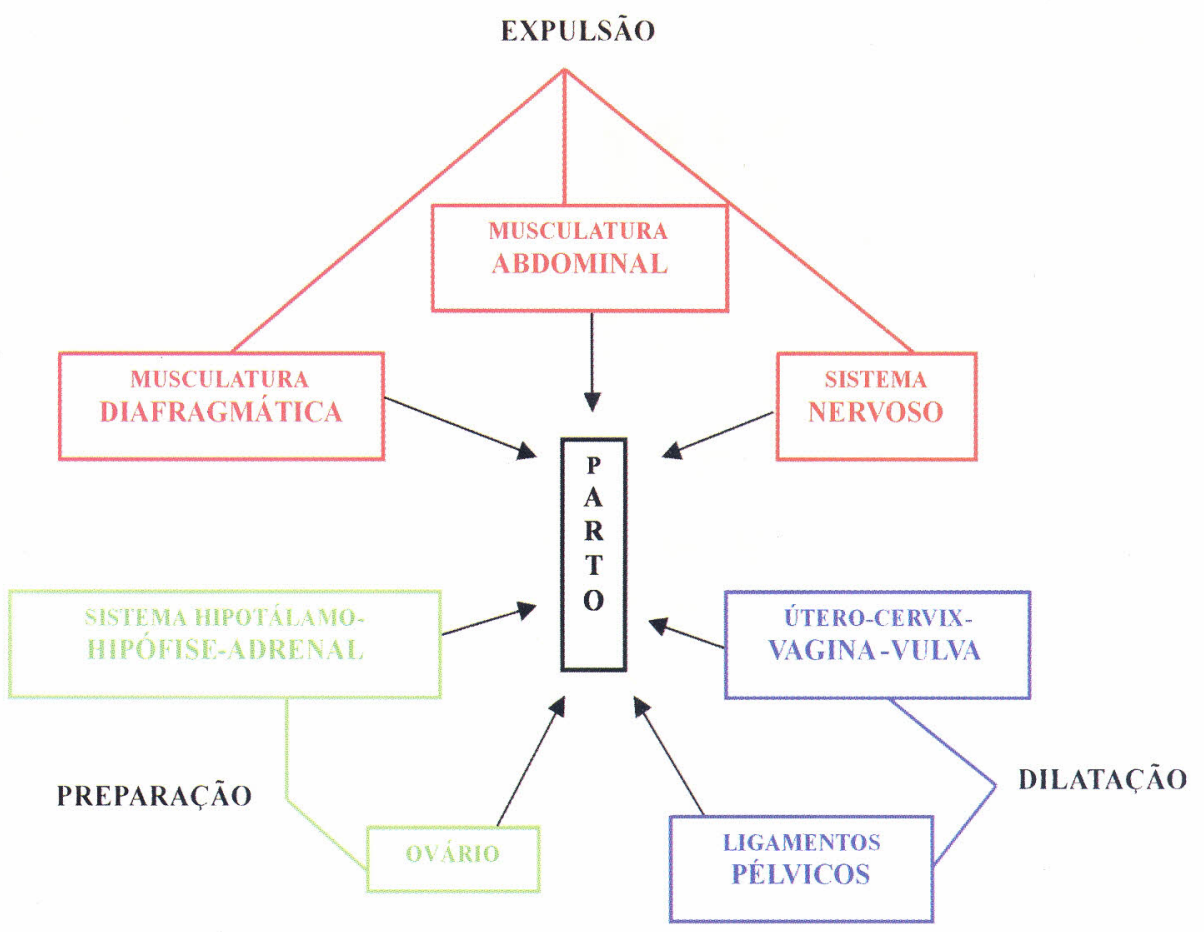


mais. Didaticamente pode ser dividido em 3 estágios: no primeiro, ocorre a rotação e extensão da cabeça, pescoço e membros torácicos para a posição dorsal ou superior; no segundo, o potro insinua-se e ocupa os espaços na via fetal mole e dura, para que ocorra a definitiva expulsão no terceiro estágio, marcadamente um reflexo mecânico/nervoso.

Nos eqüinos, de forma geral, em 95 a $97 \%$ dos partos normais a estática fetal predominante é a apresentação longitudinal anterior, posição superior e atitude estendida. Qualquer alteração nesta disposição, constitui-se em distocia, exigindo intervenção imediata, pois a permanência do potro por um período de 30 a 40 minutos entre o estágio I e II do parto é suficiente para provocar sua morte por asfixia, em consequiência do descolamento da placenta epitélio corial difusa.

Diante da distocia de causa materna (pouco comum na égua) ou de causa fetal, é fundâmental a realização de rápido, porém seqüencial exame obstétrico. Procede-se a identificação do animal, anamnese e exame geral, constituído basicamente de aferição da temperatura corporal, inspeção geral, auscultação respiratória, cardíaca e do aparelho digestório, observação e palpação da vulva, períneo, ligamento sacro-isquiático e inspeção da cauda, atentando para grau de umidade, lóquio aderido ou odores anormais. A glândula mamária merece destaque e avaliação especial principalmente com relação a edema, presença e aspecto do colostro. Testes específicos podem ser instituídos posteriormente. Finalmente, após rigorosa higienização do períneo, promover o exame obstétrico interno específico com o objetivo de avaliar as condições de dilatação e lubrificação do canal do parto e estimar a viabilidade e estática do produto. Somente após estas providências será possível estabelecer um diagnóstico, prognóstico e instituir a manobra obstétrica que a situação requeira.

As opções de tratamento, no caso específico das éguas, são limitadas, destacando-se a repulsão e correção das anomalias dos membros, cabeça e pescoço, a tração forçada, a fetotomia parcial ou total e a operação cesariana, como formas de terminalizar um parto laborioso. Deve ser ressaltado que a manipulação deve ser feita com o máximo de cuidado, utilizar lubrificantes específicos e, se houver necessidade, lançar mão de protocolos anestésicos.

Relatam-se, a seguir, algumas emergências obstétricas que merecem destaque dentre os inúmeros acontecimentos associados ao parto distócico, sem a pretensão que o assunto esteja esgotado. As manobras obstétricas e as intervenções terapêuticas ou ci- rúrgicas dos problemas abordados a seguir merecem capítulo especial.

\section{Conseqüências do parto distócico}

\section{Hemorragia via vagina}

Durante a condução de parto que exija manipulação obstétrica, discreta hemorragia pode ser evidenciada, proveniente de lacerações lineares da mucosa vaginal, ricamente vascularizada e edemaciada, em virtude do momento fisiológico da fase preparativa de parto. A ruptura do cordão umbilical também propicia o aparecimento de sangue. Esta situação é observada com freqüência após a execução de tração forçada, especialmente nos casos de o produto ser absoluto ou relativo grande.

A hemorragia pode ser profusa se houver lesão na parede de grandes vasos da vulva, vestíbulo e vagina ou da cérvix, resultando hematomas localizados. As pequenas escoriações e as coleções sangüíneas podem contaminar-se secundariamente e desenvolver trajetos fistulosos ou abscessos.

Episódios de hemorragia temporária e rescidivante podem ser evidenciados em animais que apresentem varizes localizadas, ocasionalmente no limite vestíbulovaginal.

O destacamento do endométrio, as perfurações da mucosa e musculares e as rupturas do útero são passíveis de ocorrer durante intervenções grosseiras, falta de devida e necessária lubrificação, uso de equipamento inadequado ou inadvertida tração da placenta fixada juntamente com o feto. Nos traumatismos severos do útero, poderá ocorrer hemorragia invisível e incontrolada para a cavidade abdominal com consequiências desastrosas para a parturiente.

Os sangramentos conseqüentes das dilacerações perineais de qualquer grau são facilmente detectáveis, podendo ser realizada a ligadura hemostática individual dos grandes vasos.

Exames ginecológicos seqüenciais devem ser efetivados nos animais cujo parto foi auxiliado, impor rigoroso tratamento durante o puerpério, pois nos casos negligenciados podem sobrevir aderências no espaço vaginal com sério comprometimento sobre a vida e capacidade reprodutiva futura da égua.

\section{Prolapsos}

A forma do útero, sua disposição anatômica, a localização dos ovários e a característica morfofuncional 


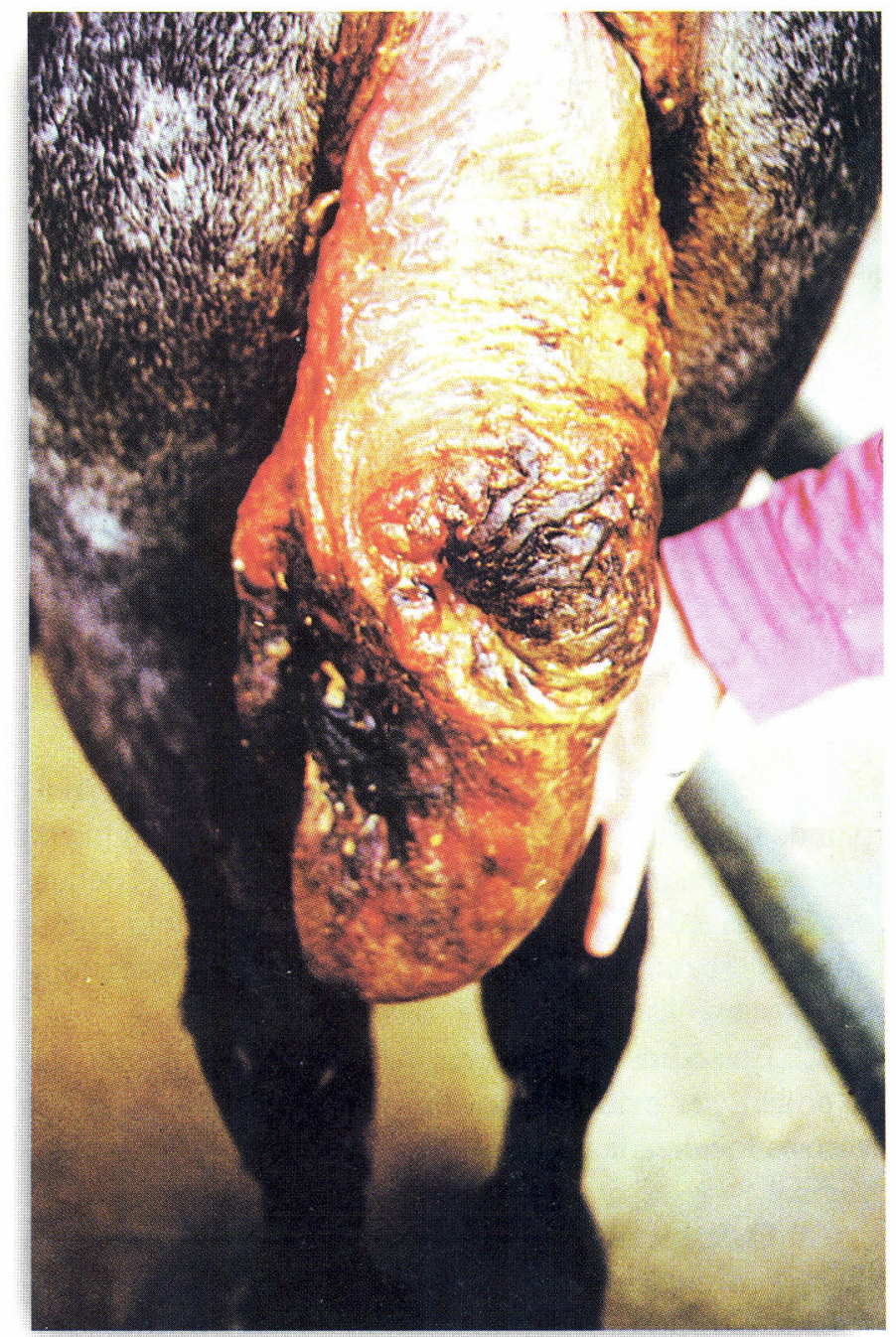

Figura 1. Prolapso total de útero. Em consequiência do tempo de exposição observam-se desidratação da mucosa e áreas de necrose superficial.

de todos os ligamentos do trato reprodutivo fazem da égua um animal pouco propenso, por natureza, a apresentar tendência para a manifestação de prolapsos de estruturas genitais (Figura 1).

As inversões da mucosa, os prolapsos parciais e totais ou cervicovaginais são raros. Projeções abauladas da mucosa vaginal através da rima vulvar podem ser observadas nos animais jovens e, na maior parte das vezes, trata-se da membrana himenal imperfurada. Prolapsos vaginais podem ocorrer durante trações forçadas na condução de partos distócicos, na fase expulsiva do parto normal ou coincidentes com contrações, consequientes de processos irritativos, inflamatórios ou excessiva manipulação.

Formações globosas avermelhadas projetando-se pela vulva, acompanhadas de esforços expulsivos, merecem criteriosa análise, podendo tratar-se de prolapso ve- sical ou mais propriamente retroflexão da bexiga urinária. A vesícula urinária exterioriza-se através da uretra, que na espécie equiina é particularmente curta e altamente distensível, especialmente no momento do parto. A inspeção cuidadosa permite definir o revestimento interno da bexiga e os ureteres com o gotejamento de urina. Os agentes causais são amplos, porém, freqüentemente responsabilizam-se os processos irritativos de qualquer natureza, manuseio excessivo, dor, tenesmo ou grave cistite. O tratamento requer o conhecimento de protocolos anestésicos, manuseio delicado na restituição do órgão à sua posição anatômica original e a completa remoção do agente causal.

O prolapso uterino completo na égua é raro, contrastando com a espécie bovina, na qual a incidência é alta. Na ampla maioria das vezes está associado ao parto distócico com retenção placentária, manifestando-se de imediato ou algumas horas após a expulsão. Como agravante, é possível haver associação com prolapso retal, eversão de bexiga ou ruptura uterina (Figura 2). O animal poderá manifestar sinais e sintomas de dor, tenesmo, ansiedade, aumento da frequiência cárdio-respiratória, prostração, hemorragia, choque hipovolêmico, redundando em óbito. Esta situação constitui-se em emergência obstétrica, exigindo rápida e decisiva atuação profissional. A fertilidade futura dos animais acometidos e tratados com sucesso irá depender do grau de dano endometrial e dos procedimentos terapêuticos impostos.

\section{As lacerações ou dilacerações}

As lacerações podem ser superficiais ou profundas, pontuais ou lineares, contidas ou extensas e potencialmente ocorrem em qualquer segmento da via fetal mole, que consiste dos cornos e corpo uterino, cérvix, vagina, vestíbulo e complexo contíguo vulva/períneo.

Os acidentes superficiais com sede no útero são dificilmente diagnosticados e, às vezes, percebidos pelo toque digital. A reversão é espontânea à medida que progride a involução uterina no puerpério. As lesões profundas são altamente comprometedoras da integridade física e viabilidade reprodutiva da égua em virtude da hemorragia, formação de aderências do útero aos órgãos adjacentes e eventualmente peritonite. Contaminação secundária ao puerpério patológico, especialmente nas condições de tratamentos mal executados, fatalmente evoluirá em necrose tecidual, piometra ou endometrite crônica.

A cérvix tem forma anelar singular e nas lacerações superficiais a expectativa é a resolução espontânea 


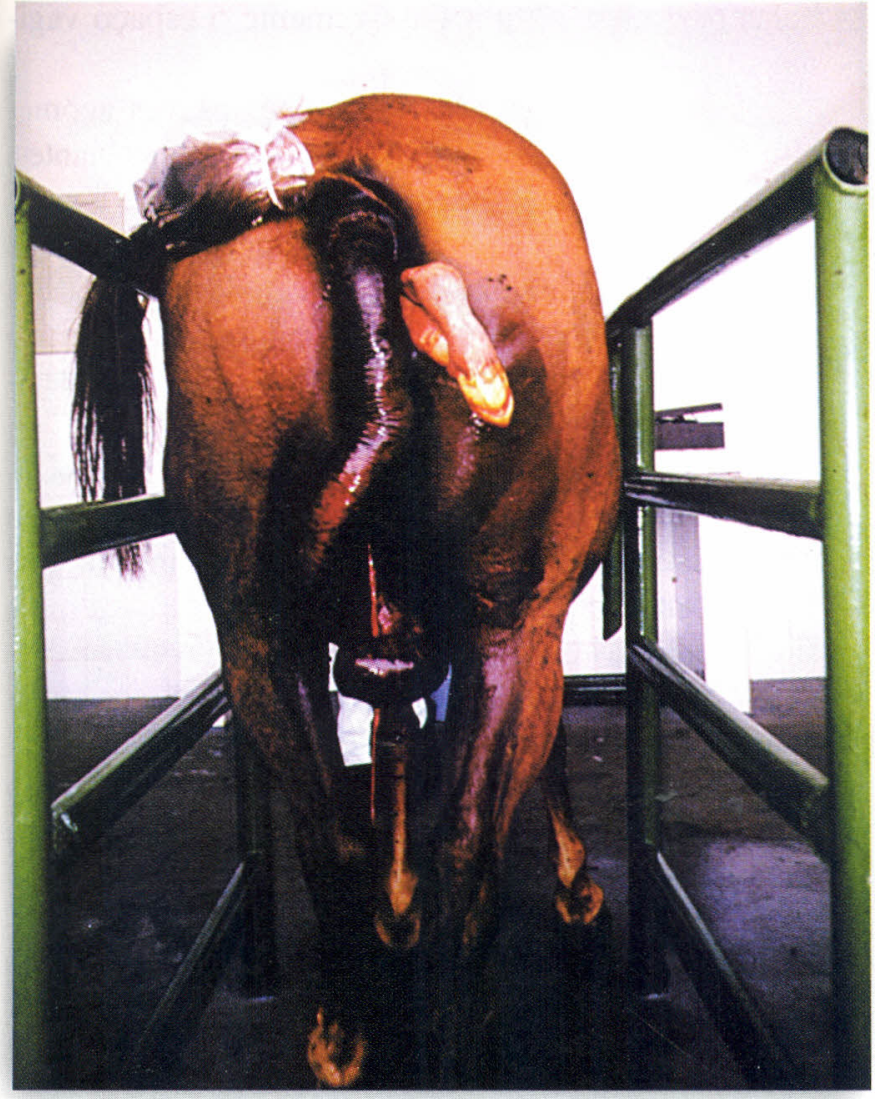

Figura 2. Prolapso de amplo segmento intestinal associado à distocia de causa fetal.

rápida, graças à extrema capacidade regenerativa da mucosa. Em situações particulares é possível a formação de aderências, tabiques ou pregas, reduzindo a luz cervical ou ocasionando deformações. Estenoses totais já foram observadas, represando o conteúdo intra-útero. As lesões profundas determinam a perda de competência funcional cervical, impedindo a concepção ou impossibilitando a manutenção da gestação. Estes acidentes acontecem durante o transcurso de um parto normal; entretanto, estão mais freqüentemente associados com a tração forçada de potros absolutos ou relativos grandes, produtos que apresentem anomalias hereditárias ou adquiridas, durante manipulações imprudentes e pela realização de fetotomia. Pelo contato manual por via vaginal, 15 a 20 dias após o ocorrido, percebe-se a descontinuidade do anel cervical, sendo possível qualificar o grau de severidade e definir-se claramente o local acometido. Alternativas para a correção cirúrgica têm sido propostas e efetivadas, porém o difícil acesso funciona como o maior fator limitante de sucesso. Mediante protocolo anestésico conveniente que promova relaxamento do aparelho reprodutivo e, utilizando-se de pinça cervical compatível, é possível tracionar e exteriorizar o anel cervical

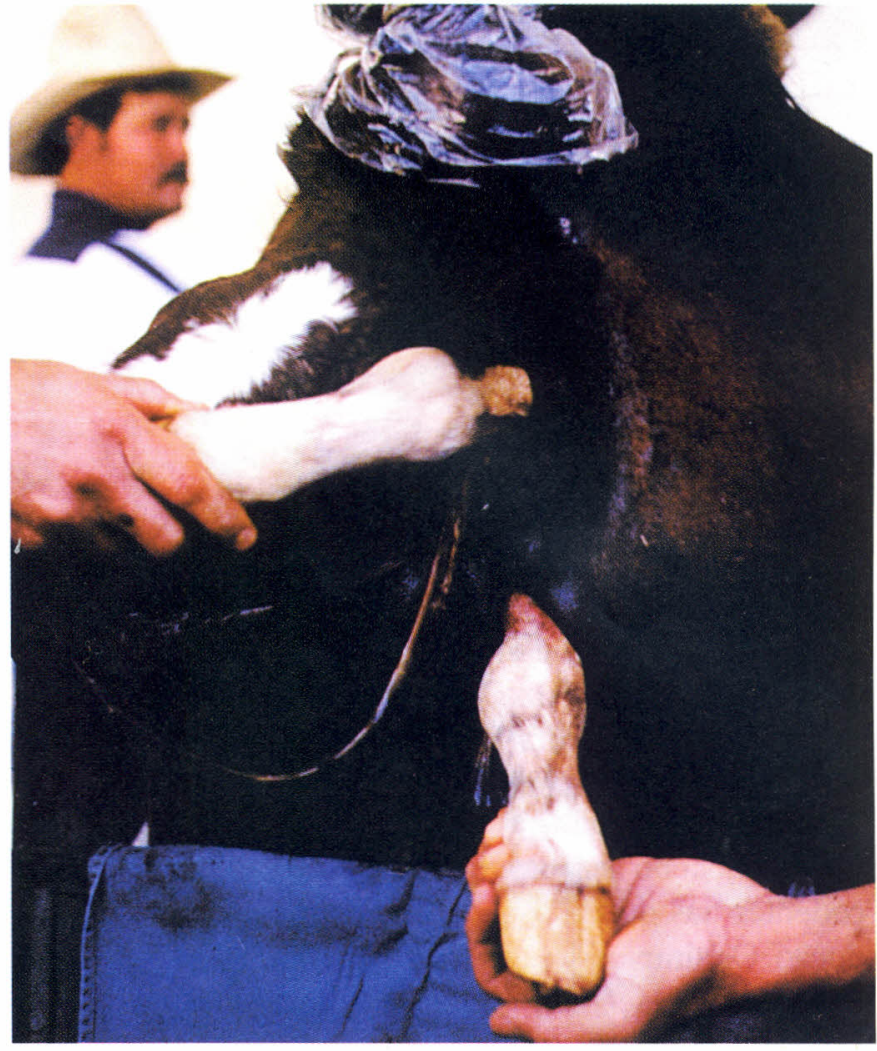

Figura 3. Parto distócico: o potro exterioriza-se com cabeça, pescoço e um membro torácico via retal e um membro torácico via vaginal. Fica evidente que se formou grande laceração reto-vaginal, preservando íntegro apenas o períneo.

até o limite do vestíbulo vaginal, permitindo melhor visualização da injúria, facilitando sobremaneira a abordagem operatória, garantindo segurança ao animal e ao profissional. Apesar dos avanços, o assunto requer novos estudos, particularmente com relação à técnica, instrumental cirúrgico, tipos de fio, padrão de sutura e cuidados e tratamento pós-operatório.

Alguns aspectos sobre as lacerações da mucosa vaginal já foram mencionados no tópico referente à hemorragia. Contudo, aderências parciais ou totais da parede tubular são passíveis de serem registradas, especialmente nos animais não submetidos a exame ginecológico condizente após o parto laborioso. Por outro lado, o vestíbulo vaginal e o meato urinário externo merecem atenção especial. Neste local, repousam a prega transversa e resquício da membrana himenal, que pode exibir graus variáveis de comprometimento em conseqüência do parto distócico (Figura 3). Na vigência de lesões graves que determinem seu desprendimento da parede látero-inferior da vagina ou quando ocorre extensa perda tecidual, fatalmente haverá refluxo de urina para o fundo vaginal, caracterizando a urovagina. Concomitantemente pode se estabelecer a vaginite, uretrite e cistite. Inú- 


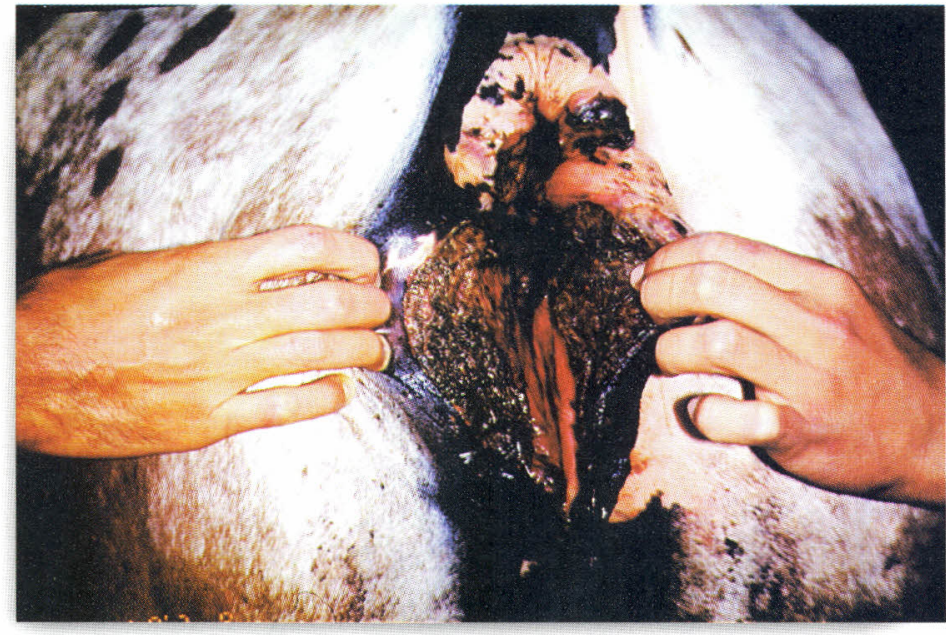

Figura 4. Laceração perineal de $3^{\circ}$ grau, 96 horas após o acidente.

meras técnicas de uretroplastia são conhecidas e propostas na literatura específica ao assunto.

A vulva, para a espécie eqüina, apresenta uma importância no aspecto reprodutivo sem os mesmos precedentes das outras espécies domésticas ou das de produção. Os simples defeitos de conformação, comprimento efetivo, angulação ou inclinação, inserção ou justaposição dos lábios, são suficientes para ocasionar subfertilidade ou infertilidade. Os desajustes vulvares permitem a passagem do ar caracterizando a pneumovagina, evidenciada inclusive pela sonoridade aspirativa emitida quando o animal se locomove.

A episiotomia é um procedimento obstétrico controlado que pode ser realizado na égua para promover maior dilatação vulvar a fim de facilitar a expulsão do produto. Deve ser evitada a incisão única linear no períneo em direção ao ânus, sob risco de haver lacerações incontroladas. Preferencialmente, procedem-se incisões oblíquas lateralmente à comissura dorsal ou superior da vulva. Terminado o parto, aplicam-se pontos de sutura na mucosa e pele, reconstituindo o local. A perfeita simetria deve ser observada, evitando-se deformações.

As lacerações ocorridas na porção mais externa do aparelho reprodutor feminino são classificadas como de primeiro, segundo ou terceiro grau, em sequiência progressiva de severidade (Figura 4). Aquelas de grau um envolvem a lesão da mucosa dorsal do vestíbulo vaginal e da porção superior da vulva, incluindo a pele com mínimo dano muscular. Lacerações de segundo grau compreendem a ruptura da musculatura vulvo-vestibular, especialmente do corpo perineal, preservando a integridade do assoalho retal e do esfincter anal. Nas dilacerações de terceiro grau, ocorre a divisão traumática da parede dorsal da vagina, do assoalho retal, esfíncter anal e corpo perineal, com conseqüente perda de tecido. As sí- balas passam a invadir passivamente o espaço vaginal.

Freqüentemente as lacerações graves acometem as primíparas; contudo, há fatores determinantes, como o feto com os membros cruzados sobre a nuca, animais com estreitamento vulvar congênito, éguas que foram previamente submetidas à vulvoplastia e naqueles animais que já haviam apresentado laceração no parto anterior, pois é esperada ligeira estenose luminal devida à perda tecidual e à retração cicatricial.

Em algumas situações as rupturas são localizadas, caracterizando a fístula reto-vaginal, consistindo em orifício de diâmetro variável, comunicando os dois trajetos anatômicos. Podem permitir a passagem de síbalas inteiras ou do caldo fecal, detectáveis no conduto e fundo vaginal (Figura 5). É evidente que o prejuízo reprodutivo pode agravar-se durante o estro, quando ocorre relaxamento cervical fisiológico, possibilitando o ingresso deste contaminante ao útero. As distocias de causa fetal ou o movimento brusco dos membros no ca-

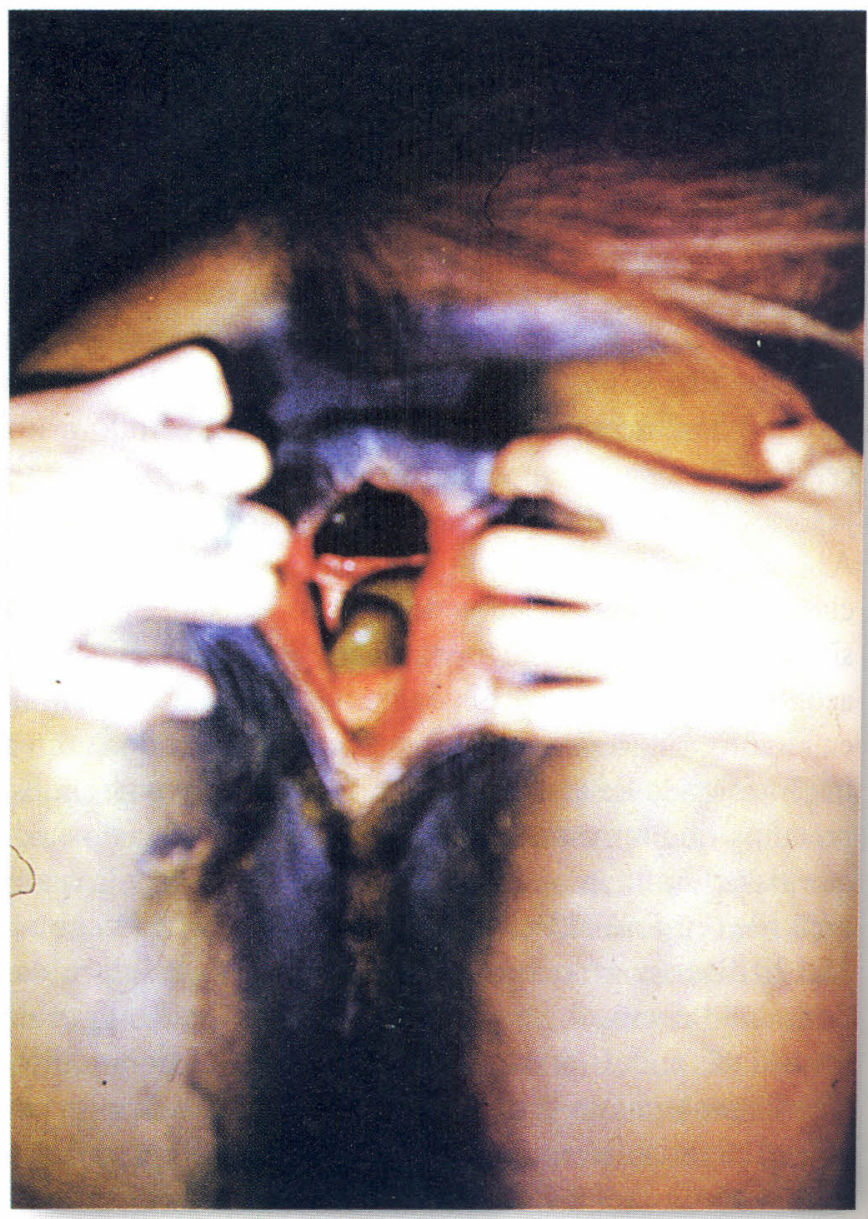

Figura 5. Laceração perineal de $3^{\circ}$ grau, 60 dias após o acidente. Notam-se a presença de síbalas no espaço vaginal e a completa regeneração da mucosa. 


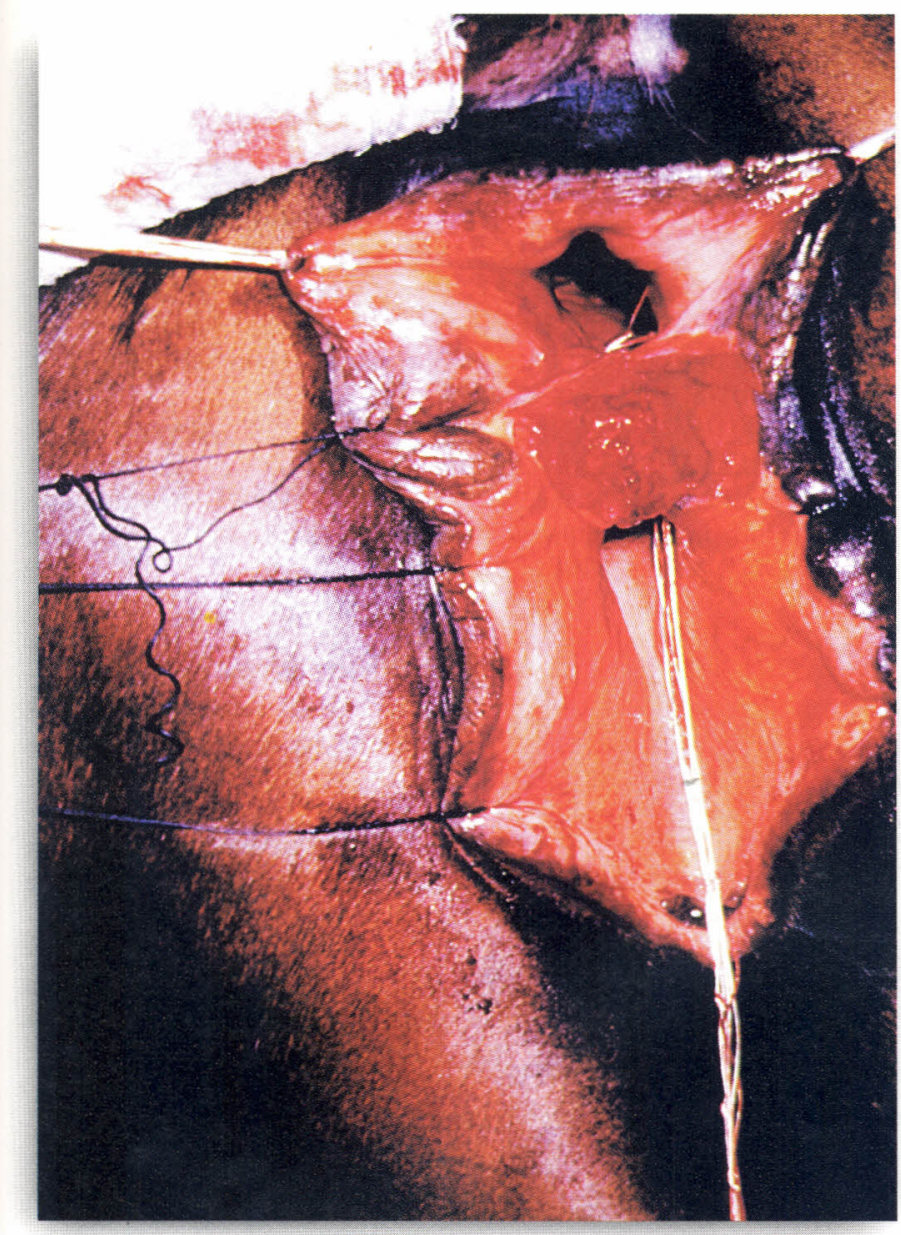

Figura 6. Detalhe da reconstituição cirúrgica da dilaceração perineal de $3^{\circ}$ grau.

nal do parto são os responsáveis por este acidente. $\mathrm{Na}$ literatura disponível estão descritos vários modelos de técnica reparativa.

As dilacerações completas, por se tratarem de lesão grave, preocupam os técnicos e criadores até pelo aspecto da ferida. Se o acidente for constatado imediatamente pós-parto, muitos profissionais optam pela sutura reconstitutiva imediata. Ultrapassado o período de 12 horas o local deve ser tratado como ferida aberta, usando-se produtos isentos de fatores irritativos até a completa regeneração das mucosas vaginal e retal, que pode demorar de 30 a 60 dias, quando será possível a execução de cirurgia plástica reconstitutiva.

A técnica básica de tratamento foi pioneiramente proposta por Gögtze, em 1929. Caslick, em 1937, relatou modelos técnicos para reparos em defeitos vulvares. Modificações foram propostas por inúmeros autores até os dias atuais (Figura 6).

As complicações pós-operatórias incluem: a retenção de fezes devida à dor, deiscência da sutura por contaminação ou pressão da constipação, trombose com conseqüente necrose tecidual, prolapso retal, eversão da bexiga urinária e infertilidade (Figura 7). Esta última pode ser seqüela da contaminação uterina sofrida pela presença de fezes do momento do parto até a realização da cirurgia.

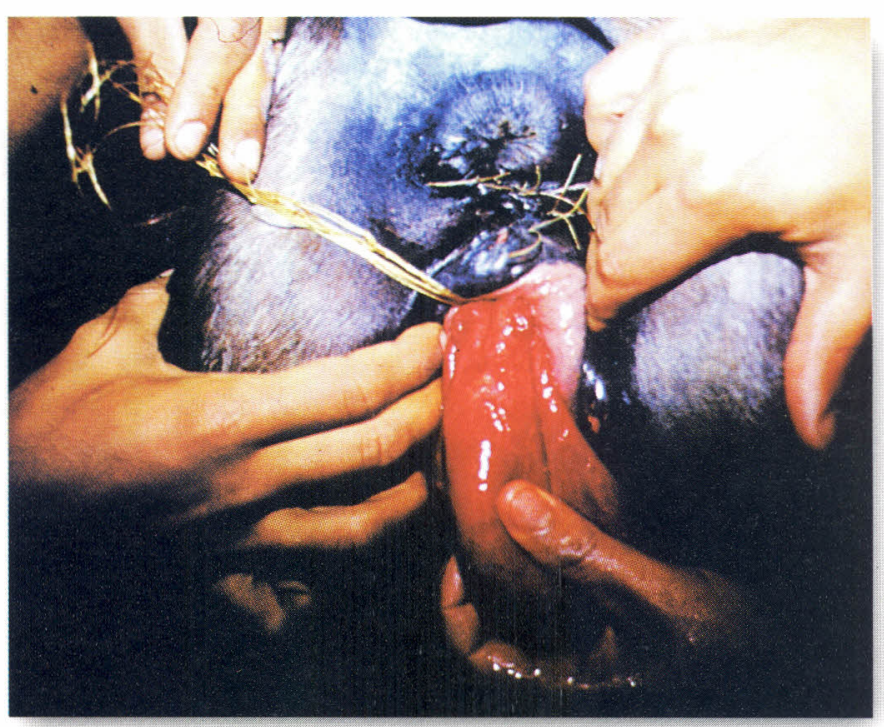

Figura 7. Retroflexão da bexiga urinária após cirurgia plástica reconstitutiva do espaço vaginal e retal - laceração de $3^{\circ}$ grau.

\section{SUMMARY}

The objective of this study was to review the classical concepts of normal and dystocic parturition, describing the main obstetric emergencies in mares.

Key words: mares, parturition, puerperal hemorrhage, prolapse, lacerations. 


\section{BIBLIOGRAFIA DE APOIO}

1 - AANES, W.A. Surgical management of foaling injuries. Veterinary Clinics of North America: Equine Practice, v.4, p. 417-38, 1988

2 - BERTHAND, C. Pneumovagina e vulvoplastia na égua. A Hora Veterinária, ano 15, n.86, p.41-6, 1995.

3 - BICUDO, S.D.; PRESTES, N.C.; PAPA, F.O.; LOPES, M.D.; ALVARENGA, M.A. Prolapso da bexiga após dilaceração perineal em égua. Relato de caso. Revista Brasileira de Reprodução Animal. V.13, n.2, p.121-4, 1989.

4 - GINTHER, O.J. Equine pregnancy: physical interactions between the uterus and conceptus. In: ANNUAL CONVENTION OF THE AMERICAN ASSOCIATION OF EQUINE PRACTITIONERS, 44, Baltimore 1998. Proceedings. AAEP, 1998. p.73-104.

5 - HOOPER, R.N.; CARTER, G.K.; VARNER, D.D.; TAYLOS, T.S.; BLANCHARD, T.L. Postparturient hemorrhage in the mare: managing lacerations of the birth canal and uterus. Equine Practice, p.57-63, January 1994.

6 - LEBLANC, M.M.; NORMAN, W.M.; VANDER-PLASSCHE, M.M.; DAELS, P.F. Selected Topics in Equine Obstetrics and Obstetrical Complication in the Mare. In: ANNUAL
CONVENTION OF AMERICAN ASSOCIATION OF EQUINE PRACTITIONERS, 38, Florida 1992. Proceedings, AAEP, p. 619-7, 1992.

7 - LEITH, G.S.; GINTHER, O.J. Mobility of the conceptus and uterine contractions in the mare. Theriogenology, v.22, p. 401-8, 1985.

8 - O'RIELLY, J.L.; MACLEAN, A.A.; LOWIS, T.C. Repair of third degree perineal laceration by a modified Goetze technique in twenty mares. Equine Veterinary Education, v.10, n.1, p.2-7, 1998.

9 - PAPA, F.O.; ALVARENGA, M.A.; BICUDO, S.D.; MEIRA, C.; PRESTES, N.C. Modificação na técnica de correção cirúrgica de dilaceração perineal de $3^{\circ}$ grau em éguas. Brazilian Journal of Veterinary Research and Animal Science, v.29, n.2, p.239-50, 1992.

10 - PERKINS, N.R.; FRAZER, G.S. Reproductive emergencies in the mare. Veterinary Clinics of North America: Equine Practice, v.10, n.3, p. 643-71, 1994.

11 - PRESTES, N.C.; BICUDO, S.D.; SARTORI F ${ }^{\circ}$, R. Prolapso retal associado a parto distócico em égua. Veterinária Notícias, v.3, n.1, p. 141-2, 1997.

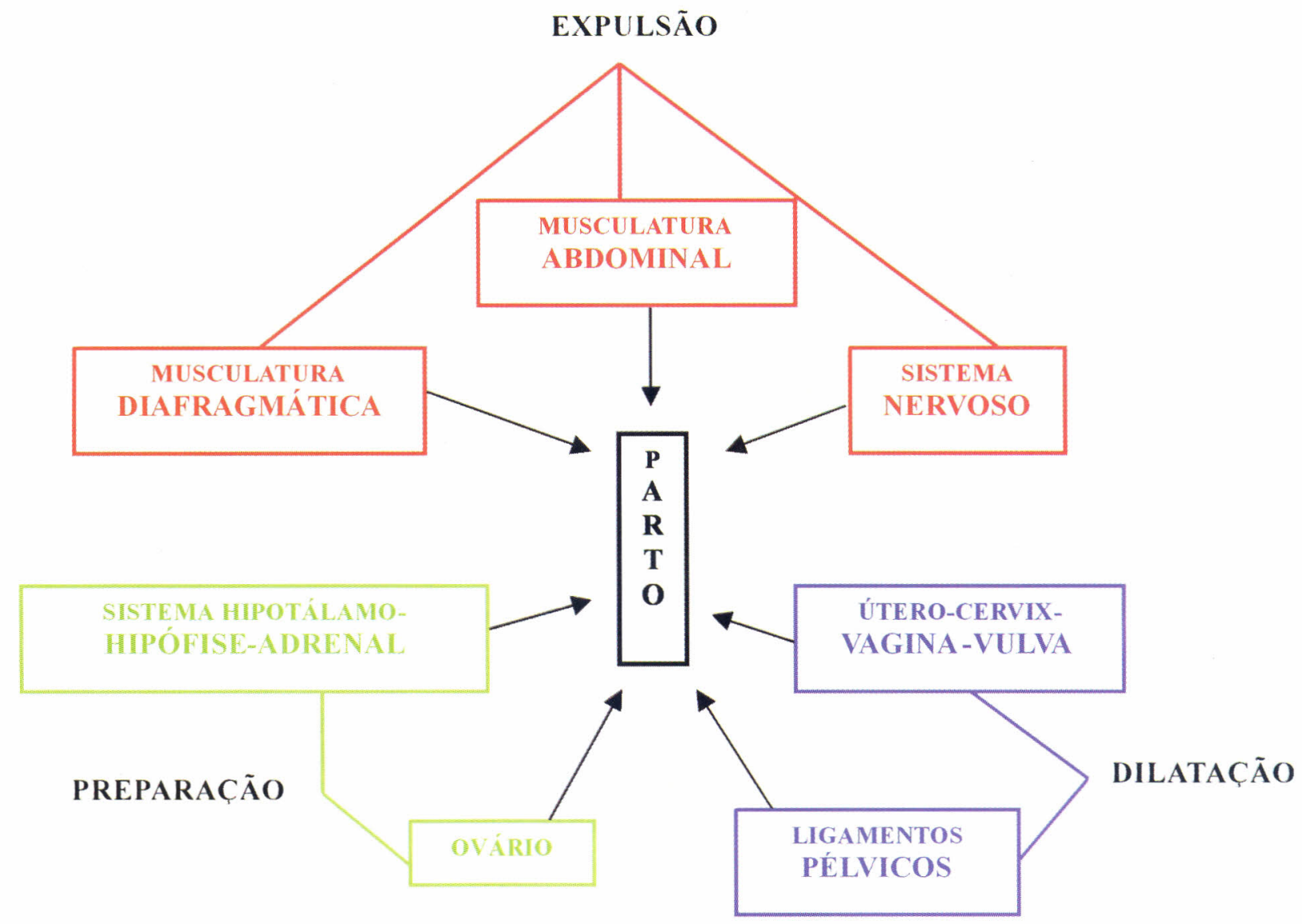

